\title{
Transmission Loss Minimization Using SVC Based on Particle Swarm Optimization
}

\author{
${ }^{1}$ Siti Amely Jumaat \\ ${ }^{1}$ Faculty of Electrical and Electronics Engineering \\ Universiti Tun Hussein Onn Malaysia \\ 86400 Parit Raja, Batu Pahat, Johor, Malaysia \\ 1amely@uthm.edu.my
}

\author{
${ }^{2}$ Ismail Musirin, ${ }^{3}$ Muhammad Murtadha Othman, \\ ${ }^{4}$ Hazlie Mokhlis \\ ${ }^{2,3}$ Faculty of Electrical Engineering \\ Universiti Teknologi MARA Malaysia \\ 40450 Shah Alam, Malaysia \\ [2_musirin@yahoo.co.uk, ${ }^{3}$ mamat505my@yahoo.com
}

${ }^{4}$ Department of Electrical Engineering

Faculty of Engineering

University of Malaya

4hazli@um.edu.my

\begin{abstract}
This paper describes optimal sizing of static var compensator (SVC) based on Particle Swarm Optimization for minimization of transmission losses considering cost function. Particle Swarm Optimization (PSO) is one of the artificial intelligent search approaches which has the potential to solve such a problem. For this study, static var compensator (SVC) is chosen as the compensation device. Validation through the implementation on the IEEE 26-bus system shows that the PSO is found feasible to achieve the task. The simulations results are compared with those obtained from the Bee Algorithm (BA) technique in the attempt to highlight its merit.
\end{abstract}

Keywords- FACTS devices, optimal sizing, particle swarm optimization, transmission loss, minimization, static var compensator.

\section{INTRODUCTION}

Nowadays, the demands for electrical energy have increased continuously yearly. The installation of new transmission networks or new power plants can solve these demands. However, there are some limitations to develop new system, i.e. installation cost, environment impact and pollution control, and the land acquisition. One of alternative solutions to respond to the demands is by using flexible alternating current transmission system (FACTS). The FACTS is a concept proposed by N.G. Hingorani [1] as a well-known term for higher controllability in power systems by means of power electronics devices. FACTS devices can provide benefits in increasing system transmission capacity and power flow control flexibility and rapidity [2].

Population base, cooperative and competitive stochastic search algorithms are very popular in this recent year in the research area of computational intelligence. Genetic Algorithm (GA) [6] and Evolutionary Programming (EP) [7] techniques are found to been established search algorithms and has been successfully implemented in solving the complex problem effectively. PSO algorithm originally is developed by Kennedy and Eberhart based on the social behaviors of animal swarms (e.g. bird blocks and fish schools) [17]. PSO applied for solving various optimization problems in electrical engineering [2, 3, 18-20].

Optimal locations of different types of FACTS devices in the power system has been attempted using different EP techniques such as Hybrid Tabu Search and Simulated Annealing (TS/SA), GA, Repetitive Power Flow method (RPF), BA and Fuzzy decision making and PSO. The maximum increase in system loadability is achieved by GA and PSO techniques with an optimal numbers of five TCSCs devices in the system. From the results it is shown that TCSC device has improved the line flows even to their thermal limits [3]. With multitype of FACTS devices installed; the reduction in total generator of fuel cost is more than the individual installed FACTS devices [4]. The hybrid TS/SA converges at a faster computation time. In [5], BA does not require external parameters such as cross over rate and mutation rate. BA gives better result in terms of speed of optimizations and accuracy of the results. BA needs the large number of trials. On the other hand, GA based approach is proposed to determine the suitable types of FACTS devices and evaluate the total costs system [6]. EP in [7] is used to identify the location of four FACTS devices. Optimal Power Flow using GA can also used to obtain the optimal locations of SVCs. The results shown that this method can be used to minimize the total cost function, including generations cost of power plants and investments costs in [8]. In [9], GA and PSO are used to optimize the parameters of TCSC. However, PSO have more advantageous than the GA. PSO gives a better balanced mechanism and better variation to the global and local exploration abilities. Moreover, it can be applied to solve various optimization problems in power system such as power 
system stability enhancement and capacitor placement problems [10].

This paper presents PSO technique for loss minimization in power system by using SVC. PSO was adopted to optimize the SVCs sizing to be installed in power transmission network. Placement of SVC is done empirically as the pilot study. The PSO and BA techniques which performed on the IEEE 26-bus RTS have indicated that the proposed methods are found to be crucial in loss minimization scheme.

\section{MATERIAL AND METHODS}

Flexible AC Transmission Systems (FACTS) devices have several types namely: thyristor controlled static compensator (TCSC), static var compensator (SVC), unified power flow controller (UPFC), static compensator (STATCOM), and thyristor controlled phase shifter transformer (TCPST) [1112]. The SVC is a shunt type FACTS device which defined as a shunt connected static var generator or absorber whose output is adjusted in order to exchange the capacitive or inductive current to maintain or control specific parameters of the power system, typically the bus voltage [13]. The SVC can inject or absorb its reactive power $\left(\mathrm{Q}_{\mathrm{SVC}}\right)$ at a chosen bus. It injects reactive power into the system $\mathrm{Q}_{\mathrm{SVC}}<0$ and absorbs reactive power from the system if $\mathrm{Q}_{\mathrm{SVC}}>0$ [14]. The working range of SVC is between +10MVar and +100MVar [21]. The SVC is modeled as a generator or absorber of reactive power as shown in figure 1 . It is modeled as an ideal reactive power injection at bus $i$, as shown in figure 2. The injected power at bus $i$ is: [15 - 16].

$$
\Delta Q_{i s}=Q_{S V C}
$$

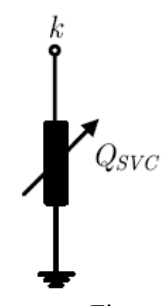

$$
Q_{\min } \leq Q_{S V C} \leq Q_{\max }
$$

Figure 1 Block diagram of SVC

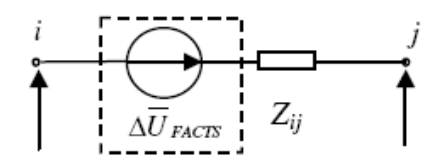

$\Delta \bar{I}_{i s} \quad \Delta Q_{i s}$

$\Delta \bar{I}_{j s}$

Figure 2 Mathematical model of SVC

\section{A. Cost of Installation}

The cost of installation of SVC devices has been mathematically formulated and given by the following equation $[2,12]$ :

$$
I C=C_{S V C} \times S \times 1000
$$

Where

$$
\begin{aligned}
& I C=\text { the installation cost of SVC devices in [US\$], } \\
& C_{S V C}=\text { the cost of SVC devices in [US\$/KVar] }
\end{aligned}
$$

Installation of SVC device can be calculated using the cost function given by $[2,6,15]$.

$$
\begin{aligned}
& C_{S V C}=0.0003 \mathrm{~S}^{2}-0.3051 \mathrm{~S}+127.38[\mathrm{US} \$ \mathrm{KV} \text { ar }] \\
& S=\left|Q_{2}-Q_{1}\right|
\end{aligned}
$$

here

$$
\begin{aligned}
& S=\text { operating range of SVC in [MVar] } \\
& Q_{1}=\text { reactive power flow through the branch before } \\
& \quad \text { SVC installation. } \\
& Q_{2}=\text { reactive power flow through the branch after } \\
& \text { SVC installation. }
\end{aligned}
$$

\section{PARTICLE SWARM OPTIMIZATION (PSO)}

The PSO provides a population-based search procedure in which individuals called particles and changes their positions. The position of each particle is presented in X-Y plane. Each particle moves to the new position using velocity according to its own experience as called $P_{\text {best }}$. $G_{\text {best }}$ is the overall best value obtained so far by any particle in the population. By time to time, the PSO consists of velocity changes of each particle towards its $P_{\text {best }}$ and $G_{\text {best }}$ [18-19]. Each particle tries to modify its current position and velocity according to the distance between its current position and $P_{\text {best }}$, and the current position and $G_{\text {best }}$. After finding the best values the particle updates its velocity and position. Velocity of each particle can be modified by equation (5) $[2,3,20]$.

$$
\begin{aligned}
v_{i}^{k+1}=w & \times v+c_{1} \times \text { rand }_{1} \times\left(P_{\text {best }_{i}}-s_{i}^{k}\right) \\
& +c_{2} \times \text { rand }_{2} \times\left(G_{\text {best }_{i}}-s_{i}^{k}\right)
\end{aligned}
$$

where

$$
\begin{aligned}
v_{i}^{k+1}= & \text { velocity of particle } t \text { at iterations } \\
w= & \text { weight function } \\
\mathrm{c}_{1} \text { and } \mathrm{c}_{2}= & \text { weight coefficien } \mathrm{t} \text { both equal to } 2 \\
\operatorname{rand}_{1} \text { and rand }{ }_{2}= & \text { random number between } 0 \text { and } 1 \\
\mathrm{~s}_{\mathrm{i}}^{\mathrm{k}}= & \text { current position of particle } i \text { at iteration } k \\
P_{\text {best }}= & \text { best position of particle } \mathrm{i}-\text { th up to the } \\
& \text { current iteration } \\
G_{\text {best }}= & \text { best overall position found by the particle } \\
& \text { up to the current iteration. }
\end{aligned}
$$

Weight function is given by (6) $[2,3,14,20]$

$$
w=w_{\max }-\frac{w_{\text {max }}-w_{\text {min }}}{\text { iter }_{\text {max }}} \times \text { iter }
$$


where

$$
\begin{aligned}
w_{\text {max }} & =\text { initial weight equal to } 0.9 \\
w_{\text {min }} & =\text { initial weight equal to } 0.4 \\
{ }^{\text {iter }}{ }_{\text {max }} & =\text { maximum iteration number, and } \\
\text { iter } & =\text { current iteration number. }
\end{aligned}
$$

The new position can be modified (7)

$$
s_{i}^{k+1}=s_{i}^{k}-v_{i}^{k+1}
$$

The computation procedure for the developed PSO algorithm takes the following steps [10]:

\section{Step 1: Generation of initial condition of each particle.}

Initial searching point $\left(s_{i}{ }^{0}\right)$ and velocities $\left(v_{i}{ }^{0}\right)$ of each particle are usually random within it range. The current searching point is set to $P_{\text {best }}$ for each particle. The best evaluated value of $P_{b e s t}$ is set to $G_{b e s t}$, and the best value is stored.

\section{Step 2: Evaluation of searching point of each particle.}

The objective function is evaluated for each particle. If the value is better than the current $P_{\text {best }}$ of the particle, the $P_{\text {best }}$ value will be replaced by the current value. If the $P_{\text {best }}$ value is better than the current $G_{\text {best }}, G_{\text {best }}$ will be replaced by the best value and the best value is stored.

\section{Step 3: Modification of each search point}

The current searching point of each particle is updated using (5), (6) and (7).

\section{Step 4: Checking the exit condition.}

The current iteration number reaches the pre-determined maximum iteration number as the stopping criterion. Otherwise the process proceeds to step 2 .

\section{TEST RESULTS}

In order to realize the effectiveness of the proposed PSO technique, the IEEE 26-bus system was tested in order to find the optimal sizing of SVC. The line data and the bus data of the IEEE 26-bus system are given in [21]. The parameters of the optimization algorithm are listed in Table $1[2,3,14,20]$.

TABLE I

PARAMETERS OF OPTIMIZATIONS TECHNIQUES

\begin{tabular}{|c|c|}
\hline Parameters & PSO \\
\hline Population Size & $5,10,15,20$ \\
\hline Inertial Weight, $w$ & $0.9-0.4$ \\
\hline Constant, C1 & 2 \\
\hline Constant, C2 & 2 \\
\hline Number of iteration & 50 \\
\hline Rand1 & 0 to 1 \\
\hline Rand2 & 0 to 1 \\
\hline
\end{tabular}

The SVC installations in the transmission system to reduce the transmission loss in the system have been conducted at several load conditions subjected to buses 6,10 , and 13 . The simulation was done in MATLAB and several buses were subjected to load variations in order to realize the effect of SVCs installation with PSO as the optimization approach. Three SVCs were installed at bus 9, 22, and 24 and assigned as $x_{1}, x_{2}$ and $x_{3}$. These buses are the weak load buses in the system; having among the lowest in maximum loadability condition [21].

\section{A. Transmission Loss Reduction with SVC Installations.}

Results for transmission loss reduction when load i.e. buses 6, 10 and 13 are subjected to load variation are tabulated in

\begin{tabular}{|c|c|c|c|c|c|}
\hline \multirow{2}{*}{$\begin{array}{l}\text { Loading } \\
\text { Condition } \\
\text { (Mvar) }\end{array}$} & \multicolumn{2}{|c|}{$\begin{array}{c}\text { Total Power Loss } \\
(\mathrm{MW})\end{array}$} & \multirow{2}{*}{$\begin{array}{c}\text { SVC } \\
\text { sizing } \\
\text { (Mvar) }\end{array}$} & \multirow{2}{*}{$\begin{array}{c}\text { Cost SVC } \\
\text { (US\$/KVar) }\end{array}$} & \multirow{2}{*}{$\begin{array}{c}\text { IC } \\
10^{3} \\
\text { (US\$) }\end{array}$} \\
\hline & $\begin{array}{c}\text { without } \\
\text { SVC }\end{array}$ & $\begin{array}{l}\text { with } \\
\text { SVC }\end{array}$ & & & \\
\hline 10 & 15.3850 & 14.4923 & $\begin{array}{l}70.1274 \\
53.3082 \\
35.7547\end{array}$ & 127.1079 & 11.3470 \\
\hline 20 & 15.4610 & 14.5013 & $\begin{array}{l}93.6702 \\
15.6589 \\
37.6245\end{array}$ & 127.0875 & 12.1970 \\
\hline 30 & 15.5420 & 14.4873 & $\begin{array}{l}89.7408 \\
33.1746 \\
51.7156 \\
\end{array}$ & 127.0585 & 13.4010 \\
\hline 40 & 15.6270 & 14.4634 & $\begin{array}{l}92.7904 \\
38.7134 \\
35.5901\end{array}$ & 127.0254 & 14.7810 \\
\hline 50 & 15.7160 & 14.4918 & $\begin{array}{l}77.3363 \\
33.2339 \\
27.9203\end{array}$ & 127.0070 & 15.5480 \\
\hline
\end{tabular}
Table 2, 3 and 4. The sizing of SVCs to achieve loss reduction at several loading conditions can be referred to the same table.

TABLE 2

TRANSMISSION LOSS REDUCTION LOAD VARIATION AT BUS 6.

For instance in Table 2 with loading condition of 50MVar, the transmission loss has been reduced from $15.7160 \mathrm{MW}$ to 14.4918MW. In order to achieve this, the sizing of SVCs are 77.3363MVar, 33.2339MVar, and 27.9203MVar as indicated in the table. The cost of installation at this scenario is 15.5480 thousand US\$. From Table 2 it is observed that the value of transmission losses is decreased rapidly and the cost of installation is increased accordingly as the reactive power loading is increased. It is also shown that, with the installation of SVC the transmission loss of the bus for all loading condition has been reduced significantly. It is pretty obvious that, with the installation of SVC optimized using PSO, the transmission losses has been able reduced at all loading conditions. 
TABLE 3

TRANSMISSION LOSS REDUCTION LOAD VARIATION AT BUS 10

\begin{tabular}{|c|c|c|c|c|c|}
\hline \multirow{2}{*}{$\begin{array}{l}\text { Loading } \\
\text { Condition } \\
\text { (Mvar) }\end{array}$} & \multicolumn{2}{|c|}{$\begin{array}{c}\text { Transmission Loss } \\
(\mathrm{MW})\end{array}$} & \multirow{2}{*}{$\begin{array}{c}\text { SVC } \\
\text { sizing } \\
\text { (Mvar) }\end{array}$} & \multirow{2}{*}{$\begin{array}{c}\text { Cost SVC } \\
\text { (US\$/KVar) }\end{array}$} & \multirow{2}{*}{$\begin{array}{c}\text { IC } \\
10^{3} \\
\text { (US\$) }\end{array}$} \\
\hline & $\begin{array}{l}\text { without } \\
\text { SVC }\end{array}$ & $\begin{array}{l}\text { with } \\
\text { SVC }\end{array}$ & & & \\
\hline 10 & 15.6050 & 14.4564 & $\begin{array}{l}37.9996 \\
68.1471 \\
49.0322\end{array}$ & 127.0300 & 145.910 \\
\hline 20 & 15.6820 & 14.3921 & $\begin{array}{l}53.4529 \\
62.2557 \\
36.3690\end{array}$ & 126.9869 & 163.800 \\
\hline 30 & 15.7650 & 14.4944 & $\begin{array}{l}52.1386 \\
38.2926 \\
67.7320\end{array}$ & 126.9928 & 161.360 \\
\hline 40 & 15.8540 & 14.5080 & $\begin{array}{l}92.2504 \\
92.4660 \\
71.8296\end{array}$ & 126.9699 & 170.900 \\
\hline 50 & 16.3940 & 14.4811 & $\begin{array}{l}80.8699 \\
45.4359 \\
31.2545 \\
\end{array}$ & 126.7975 & 242.550 \\
\hline
\end{tabular}

The sizing of SVCs to achieve optimal loss reduction at several loading conditions can also be referred to Table 3 . For instance, at loading condition of 50MVar the transmission loss has been reduced from $16.3940 \mathrm{MW}$ to $14.4811 \mathrm{MW}$. In order to achieve this, the sizing of SVCs are $80.8699 \mathrm{MVar}$, 45.4359MVar and 31.2545MVAr as indicated in the Table 3. The cost of installation at this scenario is 242.550 thousand US\$. From Table 3 it is observed that the value of transmission losses is decreased while the installation cost is increased accordingly as the reactive power loading is increased.

The results of SVCs sizing to achieve optimal loss reduction at several loading conditions subjected to bus 13 can be referred to Table 4. For instance, at loading condition of 50MVar, the transmission loss has been reduced from $15.7160 \mathrm{MW}$ to $14.5014 \mathrm{MW}$. In order to achieve this value the sizing of SVCs are been proposed as 57.0969MVar, 48.6924MVar, and 28.6442MVar as indicated in the Table 4. The cost of installation at this scenario is 153.510 thousand US\$. Similar phenomenon can be observed in this case where by; Table 4 it is observed that the value of transmission losses is decreased and the cost of installation is increased accordingly as the reactive power loading is increased.

\section{B. Comparative Studies with Other Technique}

Comparative studies were conducted with respect to the results obtained using BA [21]. The results are tabulated in Table 5, 6 and 7 for load subjected to buses 6, 10 and 13. In Table 5 at loading condition of 10MVar; PSO managed to reduce the transmission loss from $15.3850 \mathrm{MW}$ to 14.4390MW, while BA managed to reduce the transmission loss to $14.3712 \mathrm{MW}$. The same scenarios can be observed as well with 20MVar and 30MVar. It is shown that, BA technique can be optimizing the transmission loss lower than PSO. However the different results can be observed at load condition of 40MVar and 50Mvar. From Table 5, at loading condition of 50MVar; PSO managed to reduce the transmission loss from $15.7160 \mathrm{MW}$ to $14.5014 \mathrm{MW}$, while BA managed to reduce the transmission loss to $14.5919 \mathrm{MW}$. From this simulation shows that the result using by PSO is lower than the BA it which indicates the capability of PSO throughout the process.

TABLE 4

TRANSMISSION LOSS REDUCTION LOAD VARIATION AT BUS 13

\begin{tabular}{|c|c|c|c|c|c|}
\hline \multirow{2}{*}{$\begin{array}{l}\text { Loading } \\
\text { Condition } \\
\text { (Mvar) }\end{array}$} & \multicolumn{2}{|c|}{$\begin{array}{c}\text { Transmission Loss } \\
\text { (MW) }\end{array}$} & \multirow{2}{*}{$\begin{array}{c}\text { SVC } \\
\text { Sizing } \\
\text { (Mvar) }\end{array}$} & \multirow{2}{*}{$\begin{array}{c}\text { Cost SVC } \\
\text { (US\$/KVar) }\end{array}$} & \multirow{2}{*}{$\begin{array}{c}\text { IC } \\
10^{3} \\
(\mathrm{USS})\end{array}$} \\
\hline & $\begin{array}{l}\text { without } \\
\text { SVC }\end{array}$ & $\begin{array}{l}\text { with } \\
\text { SVC }\end{array}$ & & & \\
\hline 10 & 15.3850 & 14.4390 & $\begin{array}{l}77.7170 \\
80.2714 \\
51.6117\end{array}$ & 127.0916 & 120.230 \\
\hline 20 & 15.4610 & 14.4790 & $\begin{array}{l}94.4202 \\
22.5720 \\
45.4510\end{array}$ & 127.0807 & 124.800 \\
\hline 30 & 15.5420 & 14.5014 & $\begin{array}{l}88.7872 \\
52.0765 \\
22.7202 \\
\end{array}$ & 127.0628 & 132.230 \\
\hline 40 & 15.6270 & 14.4825 & $\begin{array}{l}92.2982 \\
24.6392 \\
48.5287\end{array}$ & 127.0317 & 145.380 \\
\hline 50 & 15.7160 & 14.5014 & $\begin{array}{l}57.0969 \\
48.6924 \\
28.6442\end{array}$ & 127.0117 & 153.510 \\
\hline
\end{tabular}

TABLE 5

TRANSMISSION LOSS REDUCTION LOAD VARIATION AT BUS 6 PERFORMED USING PSO AND BA

\begin{tabular}{|c|c|c|c|}
\hline \multirow{2}{*}{$\begin{array}{c}\text { Loading } \\
\text { Condition } \\
\text { (Mvar) }\end{array}$} & \multicolumn{3}{|c|}{ Transmission Loss } \\
\cline { 2 - 4 } (MW) \\
\hline 10 & 15.3850 & 14.4390 & 14.3712 \\
\hline 20 & 15.4610 & 14.4790 & 14.4141 \\
\hline 30 & 15.5420 & 14.5014 & 14.4576 \\
\hline 40 & 15.6270 & 14.4825 & 14.5297 \\
\hline 50 & 15.7160 & 14.5014 & 14.5919 \\
\hline
\end{tabular}

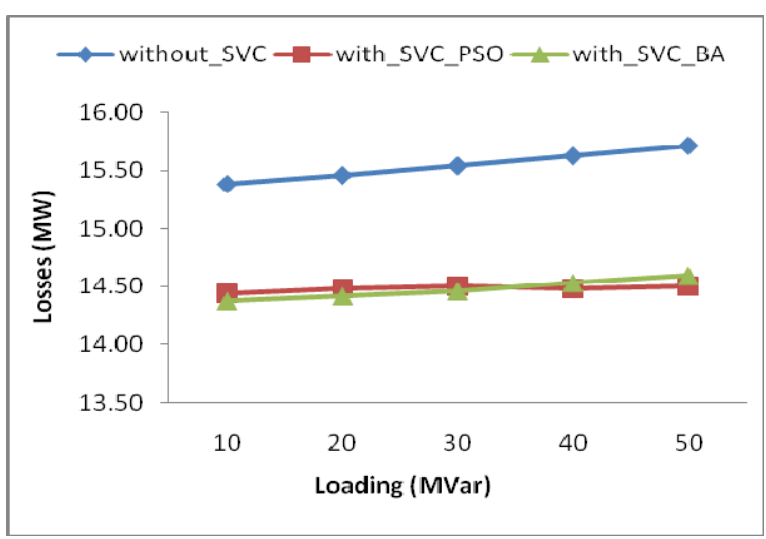

Figure 6: Results for transmission losses load variation reduction at bus 6 performed using PSO and BA 
On the other hand, Figure 6 illustrates the transmission loss in the system when the load at bus 6 is gradually increased. This is in fact exhibility the profiles of transmission loss variation performed using PSO and BA. Both PSO and BA are comparable.

In Table 6, at loading condition of 10MVar; PSO managed to reduce the transmission loss from $15.6050 \mathrm{MW}$ to 14.4564MW, while BA able to reduce the transmission loss to 14.4722MW. The same scenarios can be observed at 20MVar and $30 \mathrm{MVar}$. It is shown that, BA technique can be minimize the transmission loss lower than PSO. However the different results can be observed at load condition of 40MVar and $50 \mathrm{Mvar}$. From Table 6, at loading condition of 50MVar, PSO managed to reduce the transmission loss from $16.3940 \mathrm{MW}$ to 14.4811MW, while BA managed to reduce the transmission loss to $14.5155 \mathrm{MW}$. It is shown that the result by PSO is lower than BA. Figure 7 illustrates the transmission loss in the system when the load at bus 10 is gradually increased.

TABLE 6

TRANSMISSION LOSS REDUCTION LOAD VARIATION AT BUS 10 PERFORMED USING PSO AND BA

\begin{tabular}{|c|c|c|c|}
\hline \multirow{2}{*}{$\begin{array}{c}\text { Loading } \\
\text { Condition } \\
\text { (Mvar) }\end{array}$} & \multicolumn{3}{|c|}{ Transmission Loss (MW) } \\
\cline { 2 - 4 } & without & PSO & BA \\
\hline 10 & 15.6050 & 14.4564 & 14.4722 \\
\hline 20 & 15.6820 & 14.3921 & 14.4731 \\
\hline 30 & 15.7650 & 14.4944 & 14.4868 \\
\hline 40 & 15.8540 & 14.5080 & 14.5201 \\
\hline 50 & 16.3940 & 14.4811 & 14.5155 \\
\hline
\end{tabular}

Similar phenomenon observed at bus 13. In Table 7, at loading condition of $10 \mathrm{MVar}$, PSO able to reduce the transmission loss from $15.3850 \mathrm{MW}$ to $14.4923 \mathrm{MW}$, while BA able to reduce the transmission loss to $14.3446 \mathrm{MW}$. The same scenarios can be observed at 20MVar and 30MVar. However the different results can be observed at load condition of 40MVar and 50Mvar. From Table 7, at loading condition of 50MVar, PSO able to reduce the transmission loss from $15.7160 \mathrm{MW}$ to $14.4918 \mathrm{MW}$, while $\mathrm{BA}$ able to reduce the transmission loss to $14.5822 \mathrm{MW}$. Figure 8 illustrates the transmission loss in the system when the load at bus 13 is gradually increased. It is shown that PSO able minimize the transmission loss better than BA when loading condition is greater than 30MVar.

\section{CONCLUSION}

An approaches for transmission loss reduction by using SVC installation via PSO and BA as the optimization techniques are presented. Source code of PSO optimizations technique was developed to determine the optimal sizing of $\mathrm{SVC}$ in order to minimize the losses in the transmission

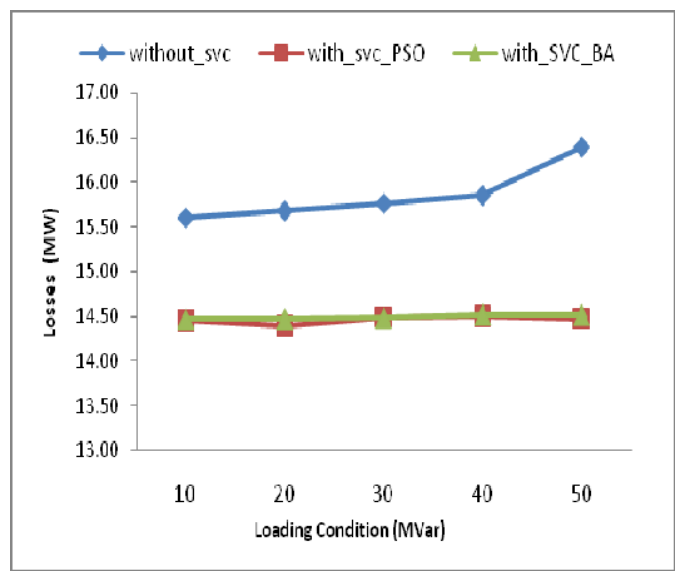

Figure 7: Results for transmission losses reduction load variation at bus 10 performed using PSO and BA

TABLE 7

TRANSMISSION LOSS REDUCTION LOAD VARIATION AT BUS 13 PERFORMED USING PSO AND BA

\begin{tabular}{|c|c|c|c|}
\hline \multirow{2}{*}{$\begin{array}{c}\text { Loading } \\
\text { Condition } \\
\text { (Mvar) }\end{array}$} & \multicolumn{3}{|c|}{ Transmission Loss } \\
\cline { 2 - 4 } (MW) \\
\hline 10 & 15.3850 & 14.4923 & 14.3446 \\
\hline 20 & 15.4610 & 14.5013 & 14.3854 \\
\hline 30 & 15.5420 & 14.4873 & 14.4543 \\
\hline 40 & 15.6270 & 14.4634 & 14.5022 \\
\hline 50 & 15.7160 & 14.4918 & 14.5822 \\
\hline
\end{tabular}

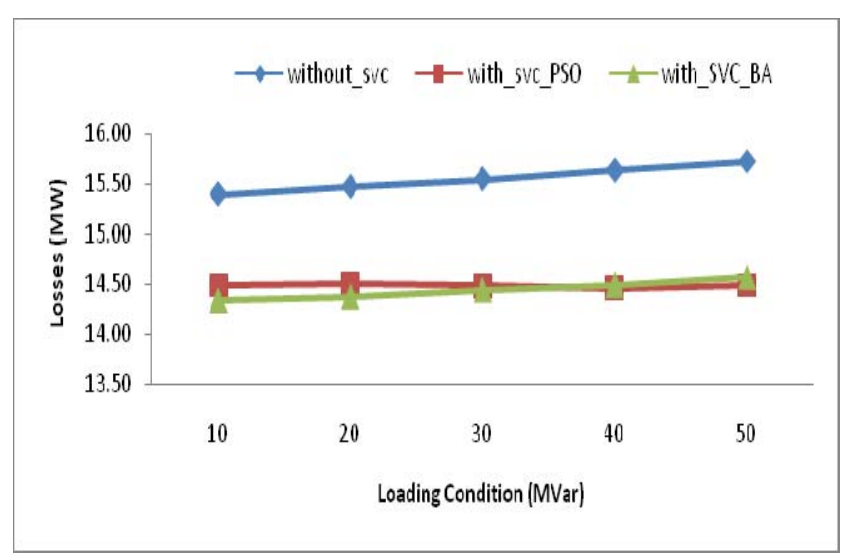

Figure 8: Results for transmission losses reduction load variation at bus 13 performed using PSO and BA

system. Besides that, the cost of installation is considered in the system. Tests are performed on the IEEE 26 bus RTS. Result shows that the implementations of PSO and BA have reduced the transmission losses of the system indicating it as a feasible technique to perform the losses optimizations. 


\section{REFERENCES}

[1] G.Hingorani, "Power electronics in electrical utilities: role of power electronics in future power systems", in Proc 1988 IEEE, Vol. 76 No, 4 April 1988, pp.481-482. 1988

[2] Saravanan. M, Slochanal. S.M.R, Venkatesh. P, Abraham, P.S, "Applications of PSO Technique for Optimal Location of FACTS Devices Considering System Loadability and Cost of Installation," in Proc $20057^{\text {th }}$ International Power Engineering Conference (IPEC). Pp. 716 - 721 Vol. 22005

[3] G.I.Rashed, H.I.Shaheen, S.J.Cheng, "Optimal Locations and Parameters Settings of Multiple TSCSs for Increasing Power System Loadability Based on GA and PSO techniques, in Proc 2007 Third IEEE International Conference on Natural Computation (ICNC 2007), 2007.

[4] P.Bhasaputra, and W.Ongsakul, "Optimal Power Flow with Multitype of FACTS Devices by Hybrid TS/SA Approach," in Proc. IEEE ICIT' 02 Bangkok Thailand, 2002.

[5] Idris. R.M, Kharuddin. A, and Mustafa, M.W, "Optimal Choice of FACTS devices for ATC Enhancement Using Bees Algorithm," in Proc. 2009, Power Engineering Conference, 2009. (AUPEC 2009). Australasian Universities 2009, pp. 1-6, 2009.

[6] Phashant Kumar Towari, and Tog Raj Sood, "Optimal Location of FACTS Devices in Power System Using Genetic Algorithm," in Proc. IEEE World Congress on Nature And Biologically Inspired Computing (NaBIC 2009), 2009.

[7] W. Ongsakul, and P. Jirapong, "Optimal allocations of FACTS devices to enhance total transfer capability using evolutionary programming," in Proc. International Symposium on Circuits and Systems, Japan, 23-26 May vol. 5 pp. 4175-4178, 2005.

[8] M.M.E. Metwally, A.A. E. Emary, F.M.E.Bendary, and M.I. Mosaad, "Optimal allocations of FACTS devices to enhance total transfer capability using evolutionary programming," in Proc. Power System Conference, 2008, MEPCON 2008, $12^{\text {th }}$ International Middle -East, pp. 1-4.

[9] S. Panda, and N.P.Padly, "Comparison of particle swarm optimization and genetic algorithm for FACTS-based controller design," Applied Soft Computing, vol 8, Issue 4, pp. 251-259, Mar. 2007.

[10] S. Chansareewittaya, and P, Jirapong, "Power Transfer Cabability Enhancement with Multitype FACTS Controller Using Particle Swarm Optimization," in Proc IEEE TENCON 2010.

[11] Ismail Musirin, Nur Dianah Mohd Radzi, Muhammad Murtadha Othman, Mohamad Khayat Idris, Titik Khawa Abdul Rahman, "Voltage Profile Improvement Using Unified Power Flow Controller via Articial Immune System", WSEAS Transaction on Power Systems, Issue 4, Volume 3, April 2008.

[12] N.G.Hingorani, and L.Gygyi, "Understanding FACTS: Concept and Technology of Flexible AC Transmission Systems," in Proc. IEEE Press, 2000, p.18. 2000.

[13] S. Auchariyamet, and S.Sirismrannukul, "Optimal Reactive Power Planning with FACTS Devices by Particle Swarm Optimization”, In Proc. $8^{\text {th }}$ International conference on Advances in Power System Control, Operation and Management (APSCOM 2009), 2009, pp. 1 6. 2009.

[14] L.J. Cai, I.Erlich, and G.Stamtsis, "Optimal Choice and Allocation of FACTS Devices in Deregulated Electricity Market using Genetic Algorithm", in Proc. Power Systems Conference and Exposition 2004. (IEEE PES 2004) 2004, pp. 201 - 207 vol.1 2004.

[15] Nor Rul Hasma Abdullah, Ismail Musirin, Muhammad Murtadha Othaman, "Static VAR Compensator for Minimising Transmission Loss and Installation Cost Calculation," Australian Journal of Basic and Applied Sciences, 4(4): 646-657, 2010.
[16] R. D. Zimmermann, and D. Gan, "Matpower a Matlab power system simulation package, User's Manual", Version 2.0, Dec. 1997.

[17] J. Kennedy, and R. Eberhart, "Particle Swarm Optimization," in Proc. 1995 IEEE International Conf. on Neural Network, vol 4, pp. 1942-1948.

[18] Chansareewittaya. S, and Jirapong, P, "Power Transfer Capability Enhancement with Multitype FACTS Controllers Using Particle Swarm Optimization," in Proc. 2010 IEEE TENCON Conference 2010, pp 42 - 47E. 2010.

[19] Hashemzadeh. H, and Hosseini. S.H., "Locating Series FACTS Devices Using Line Outage Sensitivity Factors and Particle Swarms Optimization for Congestion Management," Power \& Energy Society General Meeting, 2009 (PES '09). pp 1-6, 2009.

[20] Sundareswaran. K, Hariharan. B, Parasseri. F.P, Antony. D.S, and Subair, B, "Optimal Placement of Static VAr Compensators (SVC's) Using Particle Swarm Optimization," in Proc 2010, International Conference on Power, Control and Embedded Systems (ICPCES), 2010 , pp. $1-4,2010$.

[21] N. Othman, I. Musirin, M.A.Rahim, and Z.Othman, "Bees Algorithm Technique for Loss Minimization in Power Transmission Network Using Static Var Compensator," in Proc The $4^{\text {th }}$ International Power Enginnering and Optimization Conference (PEOCO 2010), 23-24 June 2010

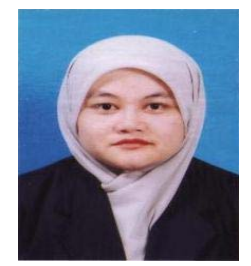

\section{BIOGRAPHIES}

Siti Amely Jumaat graduated from the Institut Tun Hussein Onn (ITTHO-UTM) with honours degree in BSc. Electrical Eng. in 2001 and MEng. (Power), UTM in 2003. She is currently is pursuing a $\mathrm{PhD}$ in power system at Universiti Teknologi MARA, Malaysia. Her research interests include power system stability, facts devices and Artificial

Intelligent techniques.

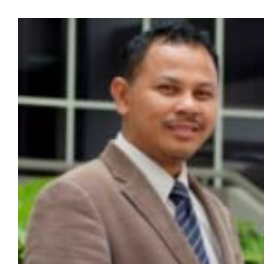

Associate Professor Dr. Ismail Musirin obtained Diploma of Electrical Power Engineering in 1987, Bachelor of Electrical Engineering (Hons) in 1990; both from Universiti Teknologi Malaysia, MSc in Pulsed Power Technology in 1992 from University of Strathclyde, United Kingdom and $\mathrm{PhD}$ in Electrical Engineering from Universiti Teknologi MARA, Malaysia in 2004. His research interest includes power system stability, optimization techniques, distributed generator and artificial intelligence.

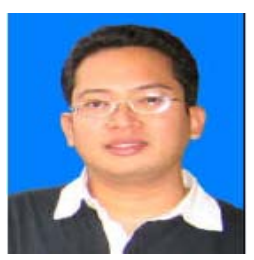

Dr. Muhammad Murtadha bin Othman received his B.Eng. (Hons) from Staffordshire University, England in 1998; M.Sc from Universiti Putra Malaysia in 2000 and $\mathrm{PhD}$ from Universiti Kebangsaan Malaysia in 2006. He currently lectures at the UniversitiTeknologi MARA, Malaysia. His area of research interests are artificial intelligence, transfer capability assessment and reliability studies in a deregulated power system.

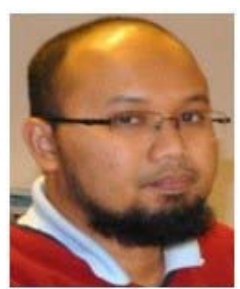

Dr. Hazlie Bin Mokhlis received M.Sc. degree from Malaya University and Ph.D degree in 2009 from Manchester University, United Kingdom. His research interest is Electrical power system (Transmission and Distribution) Power quality, stability, EMC \& Islanding 